\title{
Kale appointed CMAJ interim Editor-in-Chief
}

$\mathrm{T}$

he Canadian Medical Association and CMAJ's Journal Oversight Committee have announced that Senior Deputy Editor Dr. Rajendra Kale has been appointed CMAJ's interim Editor-in-Chief.

Kale will assume the journal's helm while a selection committee, appointed earlier this year, completes its hunt for a permanent replacement for Dr. Paul Hébert, who left the position Sept. 30. Hébert became Editor-in-Chief on Jan. 2, 2007, but announced in 2010 that he would not return to CMAJ once his five-year contract expired (www.cmaj.ca/lookup /doi/10.1503/cmaj.109-3769).

"Dr. Kale comes to this important position at an exciting time," said CMA Secretary-General and CEO Paul-Émile Cloutier. "The journal is celebrating its first century of providing medical knowledge that matters. With a higher impact factor and improved readership numbers, I believe CMAJ's future looks bright. I am confident that Rajendra, the editorial team, and the other professionals in the Publications Group will continue to deliver a high-calibre publication as we continue the search for a permanent Editor-in-Chief."

Kale was "honoured" by the appointment. "CMAJ is in an excellent position, publishing high-quality content relevant to a variety of physicians and policy-makers. The impact factor is over nine and we have a strong team of medical editors who are committed to editorial excellence."

The eight-member selection committee, chaired by CMA Boardmember Dr. Brian Brodie, is currently taking applications for the Editor-in-Chief position and is expected to soon commence interviewing candidates with an eye toward selection of a new editor in 2012. Experts say that finding a candidate with the requisite skills and knowledge to lead an academic journal can be an extremely tricky and problematic

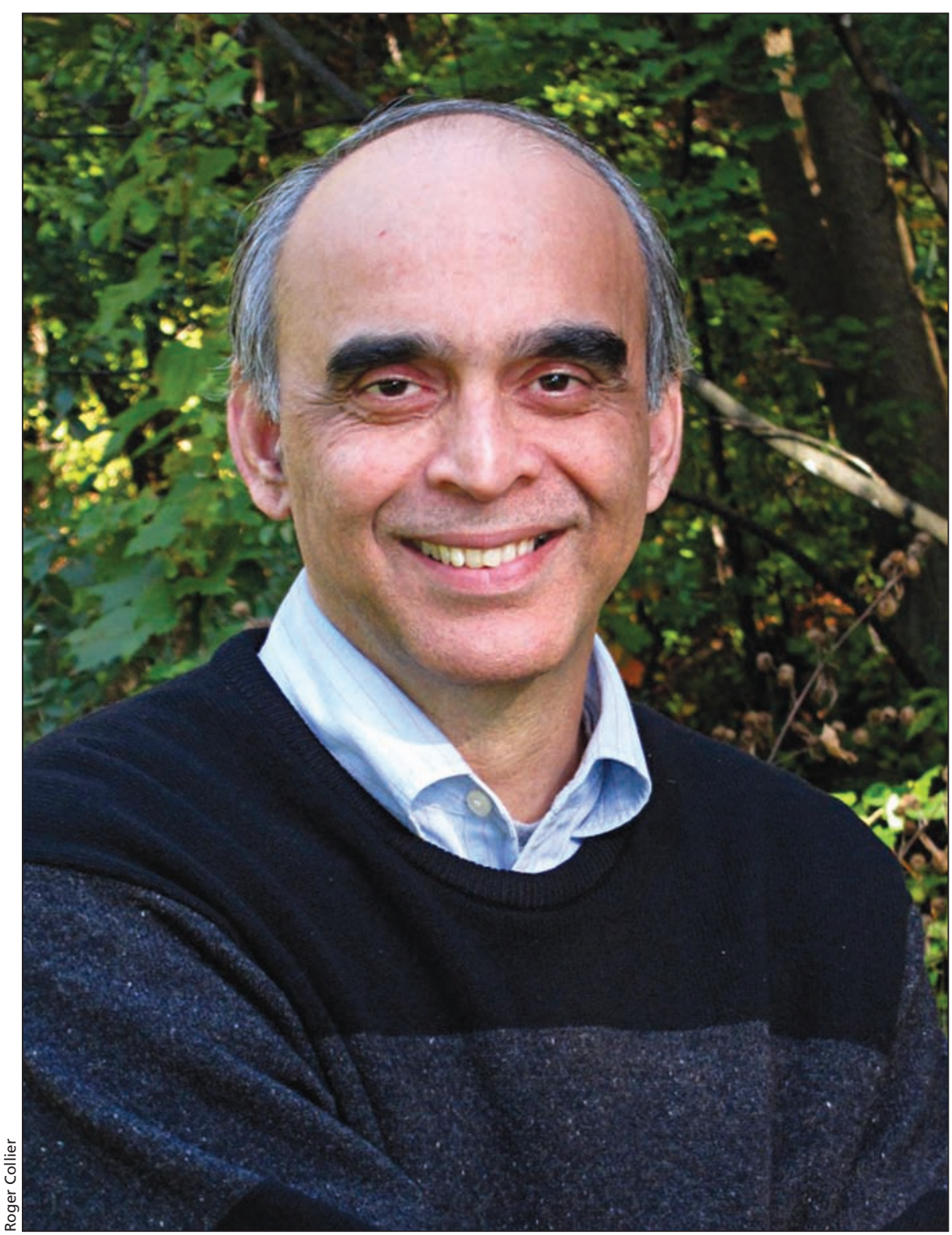

CMAJ interim Editor-in-Chief Dr. Rajendra Kale.

task (www.cmaj.ca/lookup/doi/10.1503 /cmaj.109-3785).

Kale, a native of Mumbai, India, joined $C M A J$ as senior deputy editor on Feb. 28, 2008 (www.cmaj.ca/lookup /doi/10.1503/cmaj.080544). He was formerly a senior editor at $B M J$, overseeing such sections as editorial, clinical review and practice.

A graduate of Grant Medical College in Mumbai, Kale specialized in neurology, completed a research fellowship in Dublin, Ireland and then began practising in Pune, India. He undertook a oneyear term as editorial registrar at $B M J$ in 1994, returned to practice and then joined $B M J$ on a full-time basis in 2001. - Wayne Kondro, CMAJ

CMAJ 2011. DOI:10.1503/cmaj.109-4025 